\title{
O direito de viver a própria morte e sua constitucionalidade
}

\author{
The right to live one's own death and its constitutionality
}

Elda Coelho de Azevedo Bussinguer ${ }^{1}$

Igor Awad Barcellos ${ }^{1}$

\footnotetext{
${ }^{1}$ Programa de PósGraduação em Direitos e Garantias Fundamentais, Faculdade de Direito de Vitória. R. Dr. João Carlos de Souza 779, Santa Lucia. 29.056-919 Vitória ES. elda.cab@gmail.com
}

\begin{abstract}
The article seeks to reflect on the legality of the early manifestation of will, established in Brazil through Resolution No. 1.995/12 of the Federal Council of Medicine in the face of the legislative omission and considering the possible linkage of physicians and relatives of terminally ill patients in drafting the Last Will and Testament. It examines the constitutionality of these policies and, therefore, the constitutionality of the resolution itself in light of the new Brazilian constitutional paradigm.
\end{abstract}

Key words Early manifestation of will, Last Will and Testament, The right to die, The right to life, Resolution No 1995/12 CFM
Resumo $O$ artigo se propõe a refletir acerca da legalidade da manifestação antecipada de vontade, instituída no Brasil por meio da Resolução no. 1.995/12 do Conselho Federal de Medicina, em face da omissão legislativa e considerando a possível vinculação dos médicos e familiares de pacientes terminais ao Testamento Vital. Analisa a constitucionalidade dessas diretivas e, por conseguinte, a constitucionalidade da própria Resolução à luz do novo paradigma constitucional brasileiro. Palavras-chave Manifestação antecipada de vontade, Testamento vital, Direito à morte, Direito à vida, Resolução no 1995/12 CFM 


\section{Introdução}

O atraso legislativo brasileiro ficou mais uma vez evidenciado na Resolução n. ${ }^{\circ}$ 1.995, editada em agosto de 2012, pelo Conselho Federal de Medicina $(\mathrm{CFM})^{1}$. A Resolução, que estabelece que o médico está vinculado à manifestação de vontade do paciente, expressa antecipadamente, garantindo-lhe o direito de decidir como deseja conduzir os últimos momentos de sua vida, tem o condão de resgatar a dignidade e a autonomia no final vida. A perda da consciência e da capacidade de tomar decisões e comunicá-las no estágio final da vida não pode tirar do indivíduo o poder de decidir seu projeto de vida de forma antecipada.

A Resolução enfrenta um problema que faz parte do cotidiano de médicos e profissionais da saúde que lidam com pacientes considerados terminais e fora de possibilidade terapêutica, que é o prolongamento artificial e desproporcional da vida, quando a morte, de fato, já se instalou por sua irreversibilidade, e a cultura medicalizadora da vida impõe que se continue a adiar seu momento final.

Não cabe, no âmbito deste trabalho, discutir as razões que nos levaram a essa cultura medicalizadora da vida e a esse adiamento indefinido da morte, como se inimiga fosse e não fizesse, ela também, parte do projeto de vida do indivíduo. O que se propõe, neste momento, é refletir sobre alguns pontos que se destacam na Resolução e que já começam a ser questionados tanto por profissionais médicos quanto por familiares de pacientes terminais, relativos à força vinculativa do documento em tela, denominado Testamento Vital, ou manifestação antecipada de vontade.

Antes de tudo, necessário esclarecer que não há, obrigatoriamente, a exigência de um documento escrito e registrado em cartório para que tenham validade as manifestações do paciente. O simples registro no prontuário do paciente, feito pelo médico que o assiste, deve ser considerado para efeitos legais, já que este, em razão da natureza de sua profissão, possui fé pública, não lhe sendo exigida, inclusive, a presença ou assinatura de testemunhas.

O que importa, seja em documento escrito e registrado em cartório, seja em simples registro no prontuário ou ficha médica, é que se deixe claramente registrado que o indivíduo se encontra lúcido, orientado e plenamente consciente das decisões que toma e dos desdobramentos dela.

Ao garantir que a autonomia do paciente deve ser respeitada, mesmo quando não mais estiver em condições de tomar decisões, a Resolução põe por terra uma cultura centrada no poder médico e no paternalismo do profissional, que reduz o indivíduo doente a um paciente que deve aguardar, resignada e submissamente, que deliberações acerca de sua vida sejam tomadas por outros sem que ele possa se manifestar ou decidir autonomamente como quer ser tratado ou que tipo de práticas de intervenção está disposto a aceitar.

A intenção de abrir mão desse poder decisório sobre a forma de conduzir a vida do outro pode significar um processo de democratização da Medicina, importante nos novos tempos de decisões cada vez mais difíceis e comprometedoras, ética e juridicamente. Não se está aqui a falar de democratização da conduta médica ou de banalização de um saber científico, mas de respeito à autonomia da vontade do outro que, ainda que na condição de doente, incapacitado, moribundo ou até mesmo inconsciente, tem o direito de ter sua vontade respeitada e de tomar decisões livres e autônomas.

O ponto central e norteador da Resolução é a autonomia do paciente, sujeito de sua história e de seu destino. O lugar do médico deve ser sempre o de condutor do processo terapêutico, e não o de senhor do destino de seus pacientes.

O problema, entretanto, não é simples de ser enfrentado. Enquanto o debate ético avança no interior da corporação médica, notadamente no Conselho Federal de Medicina, o problema dos limites jurídicos das Resoluções profissionais parece impor uma preocupação com a legalidade da submissão à Resolução por parte dos médicos e com os riscos inerentes a possíveis questionamentos jurídicos relativos a condutas de não intervenção.

O deslocamento do lugar central ocupado pelos médicos e, de certa forma, pelos familiares, a partir da Resolução, com nítida redução de seu poder decisório em casos de pacientes terminais sem condições de autodeterminação, faz surgir conflitos éticos que poderão fragilizar os efeitos da Resolução, causando insegurança nos profissionais. Isso poderá acontecer, por exemplo, em casos nos quais a vontade do paciente, manifesta nas diretrizes antecipadas de vontade, colide com a vontade dos familiares. Nestas situações, os médicos, diante de possíveis riscos de sofrer ações judiciais, poderão ignorar as diretrizes antecipadas de vontade do paciente, preferindo seguir as orientações dos familiares.

O trabalho se propõe, assim, a enfrentar o problema da legalidade da Resolução, seus limites e abrangência, considerando a Constituição 
Federal como ponto de partida para a análise e tendo como pressuposto teórico metodológico o novo constitucionalismo brasileiro, de base principiológica, no qual a Constituição se encontra no centro do sistema, servindo de fundamento para uma interpretação abrangente e não meramente dogmática do ordenamento jurídico.

Toma, como problema de análise, a existência de uma possível colisão entre as vontades do paciente manifestas e registradas em documento próprio ou em seu prontuário e a vontade expressa por familiares quando o doente já se encontrar fora de sua capacidade.

Adota, como ponto de partida para a análise de constitucionalidade, não a Resolução em si, esta já devidamente analisada em trabalho anterior $^{1}$, mas a própria manifestação do paciente como documento autônomo e manifestação livre de vontade acerca da condução de seu destino, quando não mais puder se manifestar, e a morte já estiver instalada.

Em síntese, o trabalho se propõe a responder às seguintes questões:

Tomando como base o que prescreve a Resolução no. 1.995/2012 do CFMำ estão os médicos juridicamente vinculados à manifestação antecipada de vontade dos pacientes terminais?

Em presença de documentos que comprovem ter o paciente terminal deixado manifesta sua vontade com relação ao tipo de intervenção/ tratamento que gostaria de receber quando não mais puder decidir e se manifestar, ficam os familiares, tais quais os médicos, a ela vinculados?

A inexistência de lei autorizativa que vincule o profissional médico à manifestação antecipada de vontade de pacientes terminais compromete a eficácia da Resolução, permitindo ao médico seguir sua própria consciência, ou do desejo dos familiares, ainda que divergente da vontade dos pacientes?

\section{O Testamento Vital não versa acerca de um suposto "direito" ao suicídio}

A partir da Resolução n. ${ }^{\circ}$ 1.995/12, editada pelo $\mathrm{CFM}^{1}$, para essa categoria profissional, a vontade do paciente passa a ser soberana, não mais podendo o médico, detentor do saber científico decisivo para a questão da vida ou da morte do paciente, estabelecer o que se procederá se suas diretivas colidirem com a do paciente, ressalvado o que dispõe o Código de Ética Médica.

A afirmativa de que o médico está subordinado à decisão do paciente não quer em absoluto dizer que este seja prescindível ao tratamento.
Muito pelo contrário. $\mathrm{O}$ médico detém o conhecimento científico do qual o paciente não dispõe e, justamente por isso, é uma figura essencial para o tratamento. No entanto, a decisão acerca de até onde o tratamento deve seguir cabe ao paciente. É justamente sobre essa "competência" decisória sobre a própria vida ou a própria morte que versa a Resolução n. ${ }^{\circ} 1.995$ do CFM ${ }^{1}$.

A formação do conteúdo decisório, por sua vez, carece da presença do conhecimento e do parecer do médico para que o paciente forme seu convencimento de maneira mais esclarecida e, por conseguinte, livre. $\mathrm{O}$ médico aparece, nesse novo contexto inaugurado pela Resolução, como um parceiro do paciente na formação da decisão mais importante de sua vida: a decisão sobre a própria morte.

Nesse sentido, grande foi a repercussão da citada Resolução em âmbito nacional. Não se estaria autorizando práticas moralmente repugnantes e até mesmo juridicamente vedadas, como a eutanásia e o suicídio assistido? Surgiria, em face dessa nova Resolução, um direito à morte? Entendemos que a Resolução não versa sobre eutanásia nem mesmo suicídio assistido. Em recente artigo publicado ${ }^{2}$, defendemos a constitucionalidade da Resolução no ${ }^{\circ} 1.995^{1}$, com base no direito à morte, o que, de forma alguma, quer dizer o direito de dispor da própria vida, ou seja, não se trata do direito ao suicídio.

Segundo entendemos, o suicídio e, por conseguinte, o dispor da própria vida é ilícito civil, além de conduta inconstitucional. Desta forma, o que, no referido artigo, definimos de direito concreto à morte nada tem a ver com o suicídio. Ao contrário disso, propomos um novo olhar acerca da morte e sua relação com a vida. Nesse novo paradigma compreensivo sobre a vida e a morte, no qual a morte é considerada como um fato decorrente da própria vida, seu término, seu fim, mas que nem por isso deixa de fazer parte dela, entendemos haver um direito concreto à morte como um exercício da vida livre. Esclareçamos tais afirmações.

Em uma breve conceituação prévia, podemos compreender o suicídio como o ato de dispor da própria vida, para nela pôr um fim. Em outras palavras, exerce-se a liberdade para dispor da vida decidindo que esta deve restar finda. Com isso, ganham relevo dois direitos fundamentais: vida e liberdade. No caso do suicídio, exerce-se a liberdade com a finalidade de dar fim à própria vida.

Entendemos pela ilicitude civil do suicídio, na medida em que nele se observa a prática do desvio de finalidade do exercício do direito funda- 
mental à liberdade. O art. 187 do Código Civil ${ }^{3}$ prevê como ato ilícito a figura do abuso de direito, que é caracterizado justamente pelo exercício de um direito de modo que se opere um desvio de finalidade. Qual seria, então, a finalidade da liberdade?

$\mathrm{O}$ art. $5^{\circ}$ da Constituição Federal ${ }^{4}$ apresenta, logo no caput, vida e liberdade, respectivamente, como os dois primeiros direitos fundamentais declarados pela Carta Mãe. Nesse sentido, embora vida e liberdade sejam normas jurídicas de mesma estatura normativa, uma interpretação sistemática da Constituição e do ordenamento jurídico como um todo nos impõe o entendimento de que a vida, além de direito fundamental, possui a natureza jurídica de fato constitutivo do direito à liberdade. Com o advento da vida, surge, para o seu titular, o direito à liberdade.

Esta, por sua vez, assegura ao seu titular a possibilidade de escolher o seu modo de viver em todos os âmbitos, a exemplo do religioso e profissional (liberdade religiosa e liberdade profissional). Se, por um lado, o direito à liberdade surge do fato constitutivo vida, por outro, é à vida que a liberdade deve servir, dando-lhe seus contornos e cores próprios com base nas decisões e escolhas de seu próprio titular.

Nesse sentido, entendemos ocorrer um desvio de finalidade, quando a liberdade é exercida de modo a atentar contra a própria vida, quando sua finalidade precípua é servi-la, ou seja, propiciar o seu pleno desenvolvimento e exercício regular (livre, portanto).

Em outras palavras, a liberdade constitucionalmente declarada assegura ao seu titular o direito de escolher como viver e não a escolha entre viver ou não viver. A vida, como direito fundamental, é indisponível, e o exercício da liberdade em vista dela dispor acarreta verdadeiro desvio de finalidade, ilícito, portanto, como prevê o Código Civil, e inconstitucional por violar a sistemática da Carta Maior.

Dessa forma, a Resolução, que vincula o médico administrativamente ao Testamento Vital, não está de modo algum dando a possibilidade de um suposto direito ao suicídio ou mesmo à eutanásia e ao suicídio assistido. Tais práticas são repugnantes à luz da moral e do ordenamento jurídico pátrio. Apesar de não versar sobre o suicídio, haveria vinculação jurídica do médico ao Testamento Vital? Sabemos que, em sede administrativa, o médico deve acatar as diretivas antecipadas do paciente, por força da Resolução 1.995/ 2012 do CFM $^{1}$. No entanto, restaria um dever jurídico do médico de acatar as determinações antecipadas do paciente? E o direito à morte? Qual seria, então, seu fundamento de validade?

\section{Omissão legislativa \\ e vinculação jurídica dos familiares}

Outra fundamental questão ganha relevo juntamente com a vinculação (ou não) jurídica do médico e é objeto deste presente artigo: os familiares em face da decisão do paciente. Estariam estes juridicamente vinculados ao Testamento Vital? Que força vinculativa teria um documento particular diante de terceiros? Haveria de fato necessidade da promulgação de uma lei para que o Testamento Vital passe a vincular terceiros?

De acordo com a Resolução, o médico está administrativamente vinculado às diretivas antecipadas de vontade. Em um primeiro momento, não há vinculação jurídica do médico com o paciente, de modo que, se o documento versar sobre conteúdo de natureza ilícita em termos legais, deve o médico optar pelo mandamento do legislador em detrimento do conteúdo da Resolução da corporação médica. Este foi um dos pontos controversos acerca da Resolução e objeto de amplo debate, como já falamos, pois, se a Resolução versasse sobre a eutanásia, por exemplo, o médico não deveria acatá-la sob pena de sanção por desobediência à lei.

No entanto, não é o caso da Resolução, ou seja, ela não ofende a lei, como esclarecemos no tópico acima. Apesar de não ofender a lei, isto é, de estar tacitamente autorizado pelo Direito, o conteúdo da Resolução não vincula o médico legalmente. Embora ele esteja eticamente obrigado a acatar as diretivas antecipadas do paciente, deixadas no Testamento Vital, ele não está legalmente obrigado a aceitá-las.

Isso se dá com base até mesmo no mandamento constitucional insculpido no art. $5^{\circ}$, II, segundo o qual ninguém será obrigado a fazer ou deixar de fazer nada senão em virtude de lei ${ }^{4}$. Desse modo, apesar de a Resolução estar em conformidade com o Direito, há de se considerar também a liberdade do médico, assegurada pela Constituição Federal: se não há lei proibindo, ele pode, juridicamente, embora não administrativamente, não acatar as diretivas antecipadas do paciente.

Em outras palavras, o médico não está legalmente vinculado ao conteúdo do Testamento Vital. Logo, em termos jurídicos, entre a liberdade (constitucionalmente assegurada) que a lei confere ao médico e a imposição administrativa do CFM, tem ele respaldo legal e constitucional 
em não acatar as diretivas antecipadas de vontade. Dessa forma, perde a Resolução força normativa, pois pode esbarrar na liberdade do médico conferida pela lei, na medida em que esta é silente, portanto, havendo liberdade neste âmbito de escolha. Esse problema poderia ser sanado com a promulgação de uma lei que versasse sobre o assunto, a exemplo de outros países, como Portugal - que já possuem legislação própria sobre o tema. No entanto, há de se perguntar se, em tempos de neoconstitucionalismo, nos quais predomina o entendimento da força normativa da Constituição, realmente haveria necessidade da promulgação de uma lei para solucionar a questão da vinculação do médico e de terceiros em geral ao Testamento Vital.

A edição da Resolução vem no sentido justamente de tentar suprir essa lacuna legislativa, apesar de não possuir força de lei, ou seja, apenas vincule os médicos na área de sua atuação profissional. Portanto, os familiares ficam de fora do âmbito normativo. Até mesmo o médico, embora não no âmbito do Conselho, possui defesa legal, no sentido de não acatamento das diretivas antecipadas do paciente.

Dessa forma, como considerar, juridicamente, as diretivas antecipadas de vontade do paciente, se os familiares, a princípio, não estão a ela vinculados e nem mesmo o médico o está legalmente? Não seriam as diretivas antecipadas "letra morta” em face da não vinculação legal dos familiares e, em último caso, do próprio médico?

\section{A constitucionalidade da Resolução n.o 1.995/2012 do CFM}

Nos tempos atuais, com o advento do neoconstitucionalismo, a Constituição não mais é considerada como uma carta programática, mas sim como norma jurídica, tendo força normativa e aplicabilidade imediata, especialmente no que concerne aos direitos e garantias fundamentais $\left(\operatorname{art} .5^{\circ}, \$ 1^{\circ}\right)^{4}$.

A problemática acerca da suposta não vinculação jurídica tanto do médico quanto dos familiares ao Testamento Vital se dá com base na pressuposição de que vinculação jurídica é sinônimo de vinculação legal. Isto nos remete ao paradigma segundo o qual somente a lei é fonte do Direito. Dessa forma, o que se está pressupondo é que "jurídico" é sinônimo de "legal”, ou seja, só é Direito o que está estabelecido em lei, o que, em outras palavras, significa, simplesmente, que "somente a lei cria o Direito". No entanto, esse paradigma já foi suplantado pelo neoconstituciona- lismo que preconiza a força normativa da Constituição e a aplicabilidade imediata dos direitos fundamentais.

Embora legalmente não regulamentadas, as diretivas antecipadas de vontade podem possuir força normativa, se buscarem amparo jurídico na Carta Mãe. Caso haja respaldo constitucional, especialmente se fundamentado em um direito fundamental, as diretivas antecipadas passam a gozar de guarida constitucional com aplicabilidade imediata ao mundo fático.

Nesse escopo, cabe a indagação: em que sentido é constitucional a Resolução n. ${ }^{\circ} 1.995$ do $\mathrm{CFM}^{1}$ ? Em que dispositivo constitucional, ou mesmo em que princípio ou preceito constitucional se baseia a Resolução do CFM?

Antes de respondermos a tais indagações, é válida a seguinte ressalva: uma vez inconteste a constitucionalidade das diretivas antecipadas de vontade, entendemos pela constitucionalidade da Resolução $n^{\circ} .1 .995$ do $\mathrm{CFM}^{1}$, pois aquela é conteúdo desta, ou melhor, a Resolução somente dispõe que o médico está administrativamente vinculado às diretivas do paciente.

O que importa, de fato, o que é mais decisivo discutir é a constitucionalidade das diretivas antecipadas de vontade, pois, uma vez provada a sua constitucionalidade, não haveria problema na vinculação administrativa do médico ao exercício de um direito fundamental do paciente.

Além disso, já provada a constitucionalidade das diretivas antecipadas de vontade, há que se discutir a vinculação jurídica do médico e dos familiares do paciente a esta, pois, uma vez entendidas como direito fundamental do paciente, poderiam os familiares se manifestar em sentido contrário e exigir que o médico não siga as diretivas do paciente? Ou mesmo, poderia o médico, juridicamente, não atender às diretivas antecipadas se estas restarem constitucionalmente provadas?

\section{A constitucionalidade das diretivas antecipadas de vontade}

Para discutirmos a constitucionalidade das diretivas antecipadas de vontade, forçosa se faz a indagação acerca de seu objeto. Em outros termos, cabe perguntar sobre o que tratam as diretivas antecipadas de vontade. Qual é seu conteúdo? Mais especificamente, e já direcionando a pergunta para a questão da constitucionalidade das diretivas, a qual direito ou mesmo a qual bem jurídico as diretivas dizem respeito?

As diretivas antecipadas de vontade, ou o Testamento Vital, versam sobre a decisão do pacien- 
te acerca de até onde deve se prosseguir com um tratamento. Isto, a princípio, não responde explicitamente ao que concerne a bens jurídicos tutelados pelo ordenamento. No entanto, à luz de um olhar mais atento, podemos notar que as diretivas dizem, em última instância, respeito à vida e à morte do paciente-aquela um bem explicitamente protegido pela Constituição Federal (art. $5^{\circ}$, caput $)^{4}$ e, segundo defendemos, esta, igualmente, um bem jurídico tutelado pela Carta Magna.

É nesse sentido que surge para nós a necessidade de um novo paradigma jurídico acerca de vida e morte como bens a serem tutelados pelo Direito. A vida geralmente é tratada como direito quase absoluto, não admitindo muitas ponderações, inclusive no sentido técnico do termo, a seu respeito. Também não estamos aqui propondo uma ponderação da vida em relação à morte. Esta é sempre vista como uma violação do direito fundamental à vida e, mesmo quando é natural, é muitas vezes considerada como um erro, algo que deveria ter sido evitado a todo custo, algo que viola, agride, atenta contra a vida.

Esse paradigma carece de ser superado. Obviamente, em muitos casos, como o homicídio, por exemplo, a violação da vida se consuma com o resultado morte, isso é inegável. Mas existem outras situações em que se torna forçoso o reconhecimento de que a morte pertence à própria dinâmica da vida, não sendo, portanto, um atentado contra esta, mas apenas o seu desdobramento natural.

É o caso de pacientes terminais. Estes são caracterizados por se encontrarem em uma situação em que a morte já se instaurou como tal. Não há possibilidade de reversão do quadro. Nesse contexto, a morte só pode se apresentar como uma decorrência da própria vida. Se esta é um direito fundamental, a decisão acerca de até que ponto devem se seguir os tratamentos não passa de uma decorrência do exercício pleno do direito à vida, ou do direito à morte, entendida, neste caso, como uma decorrência da própria vida.

Portanto, resta provada a constitucionalidade das diretivas antecipadas de vontade, pois estas versam sobre o direito fundamental à vida/ morte, tendo, assim, eficácia plena e aplicabilidade imediata, como manda o art. $5^{\circ}, \$ 1^{\circ}$ do Texto Maior ${ }^{4}$

Não obstante a constitucionalidade das diretivas antecipadas do paciente, de onde se infere o dever jurídico de observância do médico e dos familiares ao Testamento Vital?

\section{O dever jurídico e a eficácia horizontal dos direitos fundamentais}

A teoria dos direitos fundamentais é sempre exposta com muita ênfase na relação entre Estado e particular, haja vista o critério de classificação das gerações dos próprios direitos fundamentais: prestações negativas e prestações positivas, no que concerne às duas primeiras gerações. $\mathrm{Ou}$ seja, a primeira é caracterizada pelo dever de abstenção (prestações negativas) do Estado em face do particular; a segunda, pelo dever de intervenção (prestações positivas), igualmente do Estado, em face do particular. Dessa forma, é nítida a ênfase da relação vertical (Estado-particular) dada pela teoria dos direitos fundamentais.

Apesar disso, a doutrina mais atual traz como um traço característico dos direitos fundamentais a chamada eficácia horizontal. A teoria da eficácia horizontal dos direitos fundamentais surge na Alemanha. Como preconiza Bulos :

A teoria da eficácia horizontal dos direitos e garantias fundamentais, também chamada de teoria da eficácia privada, teoria da eficácia externa, teoria da eficácia entre particulares ou, ainda, teoria da eficácia em relação a terceiros, surgiu na Alemanha sob o rótulo de Drittwirkung, desenvolvendo-se de 1955 a 1960, como aprimoramento da stateaction da Suprema Corte norte-americana.

Assim sendo, os direitos fundamentais ganham, na contemporaneidade, este traço distintivo: além da eficácia em relação ao Poder Público, a dignidade humana, como mãe de todos os direitos fundamentais, deve ser observada também nas relações entre particulares. Como afirma Bulos " "[...] direitos fundamentais valem não só nas relações verticais entre indivíduo e Estado, mas também nas relações interprivadas (particular com particular)".

Existe, no âmbito doutrinário, embate acerca das duas correntes que tratam da eficácia dos direitos fundamentais, no que concerne às relações privadas. A primeira delas é a teoria da eficácia imediata, surgida em 1954, tendo como seu maior representante Hans Nipperdey ${ }^{6}$. Tal corrente preconiza que, uma vez declarados, em sede constitucional, os direitos fundamentais, em relação a outros particulares, tem eficácia imediata, isto é, não necessita de uma norma infraconstitucional que regulamente o exercício do direito constitucionalmente declarado.

Uma segunda corrente representa a teoria da eficácia indireta dos direitos fundamentais em relação a terceiros particulares. A maior crítica desta corrente à primeira é que a eficácia imediata levaria 
a uma constitucionalização de todas as relações privadas. Esta corrente surge em 1956, na Alemanha, representada por Dürig ${ }^{7}$. Segundo esta vertente teórica, só seriam aplicáveis os direitos fundamentais, declarados constitucionalmente, portanto, se seu exercício fosse devidamente regulamentado pelo legislador infraconstitucional.

Embora as críticas da segunda corrente tenham coerência inconteste, entendemos estar com a razão a primeira corrente, pois é a que mais se coaduna com a sistemática de nossa Constituição Federal $^{4}$, com especial relevo para o art. $5^{\circ}$, $\$ 1^{\circ}$ : "As normas definidoras de direitos e garantias fundamentais têm aplicação imediata". Uma vez que o próprio $\$ 1^{\circ}$, do art. $5^{\circ}$, da Constituição ${ }^{4}$ é uma norma definidora de direitos e garantias fundamentais, ele mesmo tem aplicabilidade imediata, do que decorre que as demais normas definidoras de direitos e garantias fundamentais ganham aplicabilidade imediata, como preconiza o próprio dispositivo citado. Dessa forma, entendemos estar com razão a primeira corrente. Em suma, não há necessidade de norma infraconstitucional para os direitos fundamentais terem eficácia.

Embora a eficácia dos direitos fundamentais prescinda de legislação infraconstitucional, isso não quer dizer que a atividade legislativa seja de pouca importância. Muito pelo contrário. No caso do testamento vital, a existência de uma lei infraconstitucional, regulando o exercício da manifestação antecipada de vontade, traria maior segurança aos médicos, familiares e, sobretudo, aos pacientes.

Em outras palavras, a lei infraconstitucional facilitaria a concretização do direito constitucionalmente previsto, ou seja, tornaria este direito "mais eficaz". No entanto, "mais eficaz" não quer dizer eficaz. Em síntese, embora facilitada pela legislação ordinária, os direitos fundamentais não dependem dessa legislação para ter eficácia, gozando de eficácia imediata, como preconiza o já citado $\$ 1^{\circ}$, do art. $5^{\circ}$ da $\mathrm{CF}^{4}$.

Portanto, se o Testamento Vital busca fundamento de validade em um direito fundamental, como aqui defendemos, não há que se falar em necessidade de legislação infraconstitucional para que este ganhe eficácia. Como assevera André Ramos Tavares ${ }^{7}$, “[...] não se pode negar, em situações de absoluta omissão do legislador, que os direitos 'apenas' constitucionalmente fundados sejam suporte para a solução imediata de relação privada”.

Entendemos que o caso em tela, do Testamento Vital, se enquadra perfeitamente na cita- ção precedente: embora não haja necessidade de lei para garantir a eficácia dos direitos fundamentais, a sua promulgação tornaria "mais eficaz" seu exercício. No entanto, em caso de omissão legislativa, como o caso do Brasil até então, é inegável a eficácia imediata dos direitos fundamentais nas relações privadas, ou seja, o Testamento Vital, como exercício do direito à vida/ morte, não necessita de lei para que tenha eficácia jurídica imediata, inclusive em relação a terceiros, por força da eficácia horizontal dos direitos fundamentais.

Além dos órgãos estatais (na acepção ampla aqui utilizada), também os particulares, na condição de destinatários, estão sujeitos à força vinculante dos direitos fundamentais, temática habitualmente versada sob o rótulo da constitucionalização do direito privado ou, de modo mais preciso, da eficácia dos direitos fundamentais na esfera das relações privadas ${ }^{8}$.

No cenário de força normativa da Constituição, aplicabilidade imediata e eficácia horizontal dos direitos fundamentais, é forçoso concluir pelo dever jurídico-constitucional de observância do médico e dos familiares às diretivas antecipadas de vontade.

\section{Considerações finais}

A investigação realizada acerca da constitucionalidade da manifestação antecipada de vontade, também denominada, no Brasil, de Testamento Vital, considerada à luz do novo paradigma constitucional brasileiro, permite-nos concluir que estão os médicos e os familiares vinculados às diretrizes do paciente terminal, devendo a elas se submeter, ainda que não exista lei específica capaz de dar o caráter e o sentimento de respaldo legal até muito recentemente vigente na cultura jurídica brasileira.

Com base na nova hermenêutica constitucional, surgida e sustentada pela Constituição de $1988^{4}$, e na teoria da eficácia horizontal dos direitos fundamentais, é possível concluir pela existência de fundamentação jurídica de base constitucional, capaz de sustentar que, mesmo na ausência de previsão legal de natureza infraconstitucional, estão os médicos subordinados à manifestação antecipada de pacientes terminais, ficando respaldados pela própria Constituição, em casos em que sejam juridicamente questionados acerca da legalidade de sua subordinação às diretrizes do paciente e à própria Resolução do Conselho Federal de Medicina ${ }^{1}$. 


\section{Colaboradores}

ECA Bussinguer e IA Barcellos participaram igualmente de todas as etapas de elaboração do artigo.

\section{Referências}

1. Conselho Federal de Medicina. Resolução n. ${ }^{\circ}$ 1995, de 9 de agosto de 2012. Dispõe sobre as diretivas antecipadas de vontade dos pacientes. Diário Oficial da União 2012; 31 ago.

2. Bussinguer ECA, Barcellos IA. O Direito concreto à morte em face à proteção do Direito à vida: uma reflexão sobre a constitucionalidade da resolução 1995/2012 do Conselho Federal de Medicina. In: Bussinguer EC, organizadora. Direitos humanos fundamentais. Rio de Janeiro: Lumen Juris; 2012. p. 93-104.

3. Brasil. Lei No 10.406, de 10 de janeiro de 2002. Diário Oficial da União 2002; 11 jan.

4. Brasil. Constituição da República Federativa do Brasil de 1988. Diário Oficial da União 1988; 5 out.

5. Bulos UL. Curso de direito constitucional. In: Bulos UL. 5a Edição. São Paulo: Saraiva; 2010. p. 527.

6. Tavares AR. Curso de direito constitucional. In: Tavares AR. Curso de direito constitucional. $7^{\text {a }}$ Edição. São Paulo: Saraiva; 2009. p. 499.

7. Tavares AR. Curso de direito constitucional. In: Tavares AR. Curso de direito constitucional. $7^{\text {a }}$ Edição. São Paulo: Saraiva; 2009. p. 501.

8. Sarlet IW, Marinoni LG, Mitidiero D. Curso de direito constitucional. Rev. dos Tribunais 2013; 335. 